\title{
Correction to: Recallable but not Recognizable: The Influence of Semantic Priming in Recall Paradigms
}

\author{
Jason D. Ozubko ${ }^{1}$. Lindsey Ann Sirianni ${ }^{2,3} \cdot$ Fahad N. Ahmad ${ }^{4} \cdot$ Colin M. MacLeod $^{5} \cdot$ Richard J. Addante $^{2,6}$ (D)
}

Published online: 16 February 2021

(C) The Psychonomic Society, Inc. 2021

\section{Correction to: Cognitive, Affective, \& Behavioral Neuroscience https://doi.org/10.3758/s13415-020-00854-w}

The following text has been revised in the original article under Author Contributions.

FNA contributed to the collection of data for Experiments 1, 2, and 3, the data analysis in Experiment 3, and to manuscript preparation.

Publisher's note Springer Nature remains neutral with regard to jurisdictional claims in published maps and institutional affiliations.

The online version of the original article can be found at https://doi.org/ 10.3758/s13415-020-00854-w

Richard J. Addante

Raddante@ fit.edu

1 SUNY Geneseo, Geneseo, NY, USA

2 California State University, San Bernardino, San Bernardino, CA, USA

3 Behavioral Health and Performance Laboratory, Biomedical Research and Environmental Sciences Division, Human Health and Performance Directorate, KBR/NASA Johnson Space Center, Houston, TX, USA

4 Wilfrid Laurier University, Waterloo, ON, Canada

5 University of Waterloo, Waterloo, ON, Canada

6 Department of Psychology, Florida Institute of Technology, $150 \mathrm{~W}$. University Blvd., Melbourne, FL 32901, USA 